\title{
ANALISIS BUTIR SOAL MATEMATIKA BERDASARKAN KERANGKA PENILAIAN TAKSONOMI TRENDS IN INTERNATIONAL MATHEMATICS AND SCIENCE STUDY 2019
}

\author{
Neng Nida Yulianti Alawiyah, Hetty Patmawati, Dedi Muhtadi \\ Universitas Siliwangi, Jln. Siliwangi No. 24, Tasikmalaya 46115, Jawa Barat, Indonesia \\ Email: neng.nidayulianti20@gmail.com
}

\begin{abstract}
Abstrak
Penelitian ini bertujuan untuk menganalisis butir soal Ujian Nasional matematika SMP tahun ajaran 2018/2019 berdasarkan domain konten dan kognitif taksonomi TIMSS 2019 serta menganalisis perbedaan antara soal Ujian Nasional dengan soal TIMSS. Jenis penelitian yang digunakan adalah metode penelitian kualitatif dengan subjek penelitian adalah soal Ujian Nasional matematika SMP tahun ajaran 2018/2019. Pengumpulan data menggunakan dokumentasi dan wawancara. Teknik analisis data meliputi reduksi data, penyajian data, dan penarikan kesimpulan. Hasil penelitian ini yaitu: (1) butir soal Ujian Nasional matematika SMP tahun 2018/2019 berdasarkan domain konten taksonomi TIMSS 2019, domain bilangan dengan proporsi 25\% tidak sesuai karena kurang dari TIMSS 2019 namun lingkup materi sesuai, domain aljabar dengan proporsi 32,5\% kurang ideal karena melebihi TIMSS 2019 dan lingkup materi tidak sesuai, domain geometri dengan proporsi 27,5\% kurang ideal karena melebihi TIMSS 2019 dan lingkup materi tidak sesuai, dan domain data dan probabilitas dengan proporsi 15\% tidak sesuai karena kurang dari TIMSS 2019 namun lingkup materi sesuai. (2) butir soal Ujian Nasional matematika SMP tahun 2018/2019 berdasarkan domain kognitif taksonomi TIMSS 2019, domain pengetahuan dengan proporsi $40 \%$ melebihi TIMSS namun persebaran aspek merata, domain penerapan dengan proporsi $40 \%$ sesuai dengan TIMSS dan persebaran aspek merata, dan domain penalaran dengan proporsi $20 \%$ kurang dari TIMSS dan persebaran aspek tidak merata. Selain itu terdapat tiga kategori perbedaan soal Ujian Nasional dengan soal TIMSS, yaitu: (1) domain kognitif soal UN lebih rendah dari pada soal TIMSS; (2) domain kognitif soal UN lebih tinggi dari pada soal TIMSS; dan (3) domain kognitif soal UN setara dengan soal TIMSS.
\end{abstract}

Kata Kunci: domain kognitif, domain konten, ujian nasional

\begin{abstract}
This study aims to analyze the items on the Junior High School National Mathematics Examination 2018/2019 school year based on the TIMSS 2019 tax content and cognitive domain and analyze the differences between the National Examination questions and TIMSS questions. This type of research is a qualitative research method with the subject of research is a matter of junior high school mathematics national examination 2018/2019 school year. Data collection uses documentation and interviews. Techniques for analyzing data include reducing data, presenting data, and drawing conclusions. The results of this study were: (1) items of the National Mathematics National Exam in 2018/2019 based on the TIMSS 2019 taxonomic content domain, the number domain with a proportion of $25 \%$ is not appropriate because it is less than TIMSS 2019 but the scope of the material is appropriate, the algebraic domain with a proportion of $32.5 \%$ less than ideal because it exceeds TIMSS 2019 and the scope of the material is not appropriate, the geometry domain with a proportion of $27.5 \%$ is less ideal because it exceeds TIMSS 2019 and the scoping of the material is not appropriate, and the data domain and probability with a proportion of $15 \%$ do not match because it is less than TIMSS 2019 but the scope material accordingly. (2) items of the 2018/2019 SMP National Mathematics Examination based on the TIMSS 2019 taxonomic cognitive domain, the knowledge domain with a proportion of $40 \%$ exceeding TIMSS but the distribution of cognitive aspects are evenly distributed, the domain of application with a proportion of $40 \%$ according to TIMSS and the distribution of aspects evenly, and the domain of reasoning with
\end{abstract}


the proportion of $20 \%$ less than TIMSS and the distribution of cognitive aspects is uneven. Besides, there are three different categories of National Examination questions with TIMSS questions: (1) the cognitive domain of UN questions is lower than the TIMSS questions; (2) the cognitive domain of UN questions is higher than the TIMSS questions; and (3) the cognitive domain of the UN questions is equivalent to the TIMSS questions.

Keywords: cognitif domain, conten domain, national exam

\section{Pendahuluan}

Pelaksanaan penilaian hasil belajar peserta didik didasarkan pada standar penilaian pendidikan yang berlaku secara nasional. Standar penilaian pendidikan adalah kriteria mengenai lingkup, tujuan, manfaat, prinsip, mekanisme, prosedur, dan instrumen penilaian hasil belajar peserta didik yang digunakan sebagai dasar dalam penilaian hasil belajar [1]. Instrumen penilaian hasil belajar peserta didik dapat berupa butir soal yang ada pada ulangan atau ujian. Butir soal yang digunakan tersebut haruslah butir soal yang berkualitas. Untuk mengetahui kualitas butir soal maka diperlukan analisis secara mendalam yaitu dengan melakukan kegiatan analisis butir soal karena dengan melakukan kegiatan analisis butir soal, informasi tentang kualitas masingmasing butir soal dapat diketahui secara terperinci [2]. Analisis butir soal adalah pengumpulan informasi setiap butir soal untuk selanjutnya dikaji dan ditelaah agar diperoleh soal yang bermutu [3]. Selain itu analisis butir soal juga merupakan kegiatan pengumpulan dan pengolahan data dari butir soal untuk memperoleh informasi dan menentukan kualitas butir soal berdasarkan pada acuan tertentu [4]. Sehingga analisis butir soal penting dilakukan untuk mengetahui informasi dan kualitas dari setiap butir soal terlebih berdasarkan standar Internasional agar dapat dilakukan penyesuaian.

Penyesuaian yang dilakukan salah satunya adalah dengan melakukan analisis pada soal matematika yang digunakaan di Indonesia. Terlebih pada soal-soal yang digunakan dalam kegiatan evaluasi nasional seperti soal-soal Ujian Nasional matematika SMP. Dalam hal ini soal Ujian Nasional digunakan sebagai bahan evaluasi pendidikan di Indonesia yang dilakukan pada tiap jenjang sekolah selain itu sebagai standar penilaian tertinggi di dunia pendidikan, Ujian Nasional digunakan untuk mengukur kualitas pendidikan di Indonesia [5]. Soal Ujian Nasional matematika SMP di Indonesia ada yang digunakan pada UNBK (Ujian Nasional Berbasis Komputer) dan UNKP (Ujian Nasional Berbasis Kertas dan Pensil). UNBK sendiri sudah banyak dilaksanakan di berbagai sekolah menengah termasuk di Kabupaten Tasikmalaya, namun untuk memudahkan analisis butir soal Ujian Nasional matematika SMP tersebut peneliti harus menggunakan soal Ujian Nasional yang digunakan dalam UNKP (Ujian Nasional Berbasis Kertas dan Pensil). Salah satu sekolah di Kabupaten Tasikmalaya yang melaksanakan UNKP adalah SMP Negeri 1 Puspahiang.

Salah satu studi yang dapat digunakan sebagai acuan dalam kegiatan analisis butir soal adalah taksonomi Trends in International Mathematics and Science Study (TIMSS) yang terdiri dari dua domain yaitu domain konten dan domain kognitif [6]. Trends in International Mathematics and Science Study (TIMSS) adalah studi berskala 
internasional tentang prestasi matematika dan sains peserta didik menengah pertama yaitu kelas IV dan kelas VIII yang diselenggarakan oleh lembaga independen yang melakukan studi prestasi lintas negara yaitu IEA (The International Association for the Evaluation of Education Achievement) dan dilaksanakan setiap empat tahun sekali yang bertujuan untuk mengukur prestasi matematika dan sains negara-negara peserta [7]. TIMSS terdiri dari dua domain yaitu domain konten yang terdiri dari domain bilangan, aljabar, geometri, serta data dan probabilitas, dan domain kognitif terdiri dari pengetahuan, penerapan, dan penalaran [8].

Pada penelitian TIMSS (Trends in International Mathematics Science Study) untuk matematika Indonesia pada tahun 2015 menempati posisi ke 44 dari 49 negara dengan skor 397 selain itu Indonesia pun lemah pada setiap domain konten maupun kognitif [9]. Rendahnya prestasi Indonesia tersebut bisa disebabkan oleh beberapa hal salah satunya adalah peserta didik Indonesia kurang diperkenalkan dengan soal-soal Internasional [6]. Sehingga dirasa perlu untuk mengetahui apakah soal yang digunakan oleh peserta didik di Indonesia sudah sesuai dengan soal-soal yang digunakan dalam studi Internasional. Oleh sebab itu penelitian butir soal Ujian Nasional matematika SMP berdasarkan taksonomi TIMSS perlu dilakukan. Selain itu, perbedaan soal Ujian Nasional dengan soal TIMSS pun harus dikaji, hal ini dilakukan untuk mengetahui sejauh mana perbedaan soal-soal tersebut yang menyebabkan rendahnya prestasi Indonesia di kancah Internasional.

Penelitian-penelitian mengenai analisis buitr soal yang telah dilakukan dewasa ini, banyak dilakukan terhadap buku-buku matematika dan soal UAS selain itu lebih menitikberatkan pada domain kognitif TIMSS. Penelitian yang dilakukan terhadap soal Ujian Nasional matematika SMP dan menitikberatkan pada kedua domain yaitu konten dan kognitif TIMSS belum banyak dikaji. Oleh karena itu, penulisan artikel ini bertujuan untuk membahas butir soal Ujian Nasional berdasarkan domain konten dan kognitif taksonomi TIMSS 2019 serta perbedaan soal Ujian Nasional dan soal TIMSS.

\section{Metode}

Metode yang digunakan pada penelitian ini adalah metode penelitian kualitatif deskriptif yang bermaksud memahami fenomena dengan cara deskripsi dalam bentuk kata-kata maupun bahasa pada suatu konteks alamiah [10]. Penelitian ini bertujuan untuk menganalisis butir soal Ujian Nasional matematika SMP tahun ajaran 2018/2019 secara mendalam apakah sesuai atau tidak dengan kerangka penilaian taksonomi TIMSS 2019 dan mendeskripsikan suatu keadaan apa adanya kemudian dipaparkan secara naratif.

\subsection{Subjek Penelitian}

Subjek penelitian adalah soal Ujian Nasional matematika SMP tahun ajaran 2018/2019 sebagai sumber data primer yang diambil di SMP Negeri 1 Puspahiang. Diantara subjek tersebut dipilih satu soal Ujian Nasional untuk dianalisis menggunakan teknik purposive yaitu yaitu teknik pengambilan data subjek yang dipilih berdasarkan pertimbangan tertentu [11]. Pertimbangan yang peneliti gunakan

JARME, Volume 3, No. 1, Januari 2021, 34 - 42. 
yaitu soal Ujian Nasional terdiri dari beberapa paket soal yang setiap paketnya terdiri dari 40 butir soal pilihan ganda dengan bobot dan materi yang sama sehingga peneliti mengambil satu paket soal sebagai sampel untuk dianalisis. Selain itu guru mata pelajaran matematika SMP Negeri 1 Puspahiang sebagai sumber data sekunder yang akan diwawancarai untuk mendukung hasil analisis peneliti terhadap soal Ujian Nasional

\subsection{Pengumpulan Data}

Analisis data dalam penelitian ini menggunakan metode interaktif karena aktivitas dalam analisis data kualitatif dilakukan secara interaktif dan berlangsung secara terus menerus sampai data jenuh [12]. Teknik analisis data pada penelitian ini meliputi: (1) Reduksi data, mengklasifikasikan soal Ujian Nasional matematika SMP tahun 2018/2019 berdasarkan domain konten dan kognitif taksonomi TIMSS 2019 untuk dijadikan bahan wawancara dan dijadikan sebagai dasar untuk mencarai perbedaan soal UN dan TIMSS. (2) Penyajian data, pada penelitian ini penyajian data nerupa teks yang bersifat naratif dari hasil klasifikasi, serta tabel untuk melihat proporsi soal UN. (3) Penarikan kesimpulan, yaitu mendeskripsikan hasil analisis butir soal Ujian Nasional matematika SMP berdasarkan kerangka penilaian taksonomi TIMSS 2019 sehingga dapat diketahui komposisi masing-masing domain konten dan domain kognitif yang terkandung di dalamnya serta perbedaan antara soal Ujian Nasional dengan soal TIMSS

\section{Hasil dan Diskusi}

Berdasarkan hasil penelitian terhadap soal Ujian Nasional berdasarkan taksonomi TIMSS 2019 didapat:

\subsection{Butir Soal Ujian Nasional Matematika SMP Tahun Ajaran 2018/2019 berdasarkan Domain Konten}

Setelah soal dianalisis didapatkan distribusi domain konten pada soal Ujian Nasional Matematika SMP tahun ajaran 2018/2019 yaitu 10 soal domain bilangan, 13 soal domain aljabar, 11 soal domain geometri, dan 6 soal domain data dan probabilitas, dengan persentase sebagai berikut:

Tabel 1. Distribusi domain konten pada soal UN

\begin{tabular}{llc}
\hline Domain Konten & \multicolumn{1}{c}{ Butir Soal Nomor } & Jumlah Soal \\
\hline Bilangan & $1,2,3,5,6,7,8,10,11,12$ & 10 \\
Aljabar & $4,9,13,14,15,16,17,18,19,20,21,22,27$ & 13 \\
Geometri & $23,24,25,26,28,29,30,31,32,33,34$ & 11 \\
Data dan Probabilitas & $35,36,37,38,39,40$ & 6 \\
\hline \multicolumn{1}{c}{ Jumlah } & & 40 \\
\hline
\end{tabular}


Tabel 2. Persentase domain konten soal UN

\begin{tabular}{ll}
\hline Domain Konten & Proporsi \\
\hline Bilangan (Number) & $25 \%$ \\
Aljabar (Algebra) & $32,5 \%$ \\
Geometri (Geometry) & $27,5 \%$ \\
Data dan Probabilitas (Data and Probability) & $15 \%$ \\
\hline
\end{tabular}

Hasil analisis domain konten pada soal Ujian Nasional matematika SMP tahun ajaran 2018/2019 menunjukkan bahwa domain bilangan sebanyak 10 soal yaitu pada butir soal nomor $1,2,3,5,6,7,8,10,11$, dan 12 dengan persentase $25 \%$ yang tidak sesuai dengan persentase yang ditetapkan TIMSS 2019 yaitu 30\% dengan ruang lingkup materi meliputi bilangan bulat, bilangan pecahan, perbandingan, bilangan berpangkat, bilangan bentuk akar, pola barisan bilangan, barisan dan deret yang secara garis besar semuanya sesuai dengan indikator domain konten bilangan pada TIMSS 2019. Domain aljabar sebanyak 13 soal yaitu pada butir soal nomor 4, 9, 13, 14, $15,16,17,18,19,20,21,22$, dan 27 dengan persentase $32,5 \%$ yang tidak sesuai dengan persentase yang ditetapkan TIMSS 2019 yaitu 30\% dengan ruang lingkup materi meliputi bentuk aljabar, persamaan dan pertidaksamaan linier satu variabel, himpunan, relasi dan fungsi, persamaan garis lurus, sistem persamaan linier dua variabel, namun terdapat materi UN yang tidak bisa disesuaikan atau tidak ada dalam indikator domain konten aljabar pada TIMSS 2019 yaitu materi himpunan.

Domain geometri sebanyak 11 soal yaitu pada butir soal nomor $23,24,25,26$, $28,29,30,31,32,33$, dan 34 dengan persentase $27,5 \%$ yang tidak sesuai dengan persentase yang ditetapkan TIMSS 2019 yaitu 20\% dengan ruang lingkup materi meliputi garis dan sudut, segitiga dan segiempat, teorema pyhagoras, lingkaran, bangun ruang sisi datar, kesebangunan dan kekongruenan, bangun ruang sisi lengkung, namun terdapat materi pada domain konten geometri TIMSS 2019 yang tidak ada dalam lingkup materi geometri pada soal UN yaitu translasi, refleksi, dan rotasi dengan indikator mengetahui dan menggambar transformasi geometri. Domain data dan probabilitas sebanyak 6 soal yaitu pada butir soal nomor 35, 36, 37, 38, 39, dan 40 dengan persentase $15 \%$ yang tidak sesuai dengan persentase yang ditetapkan TIMSS 2019 yaitu 20\% dengan ruang lingkup materi meliputi menyajikan data dan mendeskripsikan data dalam bentuk tabel, diagram batang, garis, atau lingkaran; ukuran pemusatan data; dan titik/ruang sampel dan peluang.

Ketidaksesuaian terjadi pada setiap domain konten dimana proporsi dari setiap domain konten pada soal UN tidak sesuai dengan yang ditargetkan oleh TIMSS ada yang kurang dan ada yang melebihi. Ketidaksesuain tersebut menyebabkan rendahnya presatasi Indonesia pada TIMSS. Ketidaksesuaian pada materi seperti terdapat materi yang belum diajarkan kepada peserta didik Indonesia dapat menjadi salah satu penyebab rendahnya pencapaian prestasi Indonesia dalam TIMSS [13].

JARME, Volume 3, No. 1, Januari 2021, 34 - 42. 


\subsection{Butir Soal Ujian Nasional Matematika SMP Tahun Ajaran 2018/2019 berdasarkan Domain Kognitif}

Setelah soal dianalisis didapatkan distribusi domain kognitif pada soal Ujian Nasional Matematika SMP tahun ajaran 2018/2019 yaitu 16 soal yang memuat domain pengetahuan, 16 soal yang memuat domain penerapan, dan 8 soal yang memuat domain penalaran. Pada 16 soal domain pengetahuan terdiri dari 2 soal recall, 1 soal recognize, 1 soal classify, 8 soal compute, 3 soal retrieve, dan 1 soal measure. Pada 16 soal domain penerapan terdiri dari 5 soal determine, 3 soal represent, dan 8 soal implement. Pada 8 soal domain penerapan terdiri dari 5 soal analyze, 1 soal integrate, dan 2 soal draw conclusion, dengan persentase sebagai berikut:

Tabel 3. Distribusi domain kognitif pada soal UN

\begin{tabular}{|c|c|c|c|c|}
\hline Domain Kognitif & Aspek & Nomor Soal & Jumlah Soal & Jumlah \\
\hline \multirow{6}{*}{$\begin{array}{l}\text { Pengetahuan } \\
\text { (Knowing) }\end{array}$} & Recall & 14,25 & 2 & \multirow{6}{*}{16} \\
\hline & Recognize & 1 & 1 & \\
\hline & Classify & 13 & 1 & \\
\hline & Compute & $\begin{array}{l}2,3,9,16,17 \\
19,29,32\end{array}$ & 8 & \\
\hline & Retrieve & $15,35,37$ & 3 & \\
\hline & Measure & 23 & 1 & \\
\hline \multirow{3}{*}{$\begin{array}{l}\text { Penerapan } \\
\text { (Applying) }\end{array}$} & Determine & $5,10,12,30,33$ & 5 & \multirow{3}{*}{16} \\
\hline & Represent & $8,11,27$ & 3 & \\
\hline & Implement & $\begin{array}{l}7,24,26,28 \\
31,36,38,39\end{array}$ & 8 & \\
\hline \multirow{6}{*}{$\begin{array}{l}\text { Penalaran } \\
\text { (Reasoning) }\end{array}$} & Analyze & $4,6,20,21,34$ & 5 & \multirow{6}{*}{8} \\
\hline & Integrate & 40 & 1 & \\
\hline & Evaluate & - & - & \\
\hline & Draw Conclusion & 18,22 & 2 & \\
\hline & Generalize & - & - & \\
\hline & Justify & - & - & \\
\hline Jumlah & & & & 40 \\
\hline
\end{tabular}

Tabel 2. Persentase domain kognitif soal UN

\begin{tabular}{llcc}
\hline Domain Kognitif & Aspek & Proporsi Aspek & Proporsi \\
\hline & Recall & $5 \%$ & \\
Pengetahuan & Recognize & $2,5 \%$ & \\
(Knowing) & Classify & $2,5 \%$ & $40 \%$ \\
& Compute & $20 \%$ & \\
& Retrieve & $7,5 \%$ & \\
& Measure & $2,5 \%$ & $40 \%$ \\
Penerapan & Determine & $12,5 \%$ & \\
(Applying) & Represent & $7,5 \%$ & \\
& Implement & $20 \%$ & $20 \%$ \\
Penalaran & Analyze & $12,5 \%$ & \\
(Reasoning) & Integrate & $2,5 \%$ & \\
\hline
\end{tabular}




\begin{tabular}{cl}
\hline Evaluate & - \\
Draw Conclusion & $5 \%$ \\
Generalize & - \\
Justify & - \\
\hline
\end{tabular}

Hasil analisis domain kognitif pada soal Ujian Nasional matematika SMP tahun ajaran 2018/2019 menunjukkan bahwa domain pengetahuan sebanyak 16 soal dengan persentase $40 \%$ yang tidak sesuai dengan persentase yang ditetapkan TIMSS 2019 yaitu 35\% dengan persebaran aspek kognitif pengetahuan pada soal UN berdasarkan TIMSS 2019 sudah merata meliputi recall (mengingat) pada butir soal nomor 14 dan 25, recognize (mengenali) pada butir soal nomor 1, classify (mengklasifikasikan) pada butir soal nomor 13, compute (menghitug) pada butir soal nomor $2,3,9,16,17,19,29$, dan 32, retrieve (mengambil) pada butir soal nomor 15 , 35 , dan 37, serta measure (mengukur) pada butir soal nomor 23. Domain penerapan sebanyak 16 soal dengan persentase $40 \%$ dan sudah sesuai dengan persentase yang ditetapkan TIMSS 2019 yaitu 40\% dengan persebaran aspek kognitif penerapan pada soal UN berdasarkan TIMSS 2019 sudah merata meliputi determine (menentukan) pada butir soal nomor 5,10,12, dan 33, represent (merepresentasikan) pada butir soal nomor 8,11 , dan 27, serta implement (mengimplementasikan) pada butir soal nomor $7,24,26,28,31,36,38$, dan 39. Domain penalaran sebanyak 8 soal dengan persentase 20\% yang tidak sesuai dengan persentase yang ditetapkan TIMSS 2019 yaitu 25\% dengan persebaran aspek kognitif penalaran pada soal UN berdasarkan TIMSS 2019 belum merata karena terdapat aspek kognitif penalaran yang tidak termuat dalam soal UN meliputi evaluate (mengevaluasi), generalize (menggeneralisasikan), dan justify (memberi alasan). Sementara aspek yang kognitif penalaran yang termuat meliputi analyze (menganalisis) pada butir soal nomor 4, 6, 20, 21, dan 34, integrate (mengintegrasikan) pada butir soal nomor 40, serta draw conclusion (membuat kesimpulan) pada butir soal nomor 18 dan 22.

Jumlah soal domain kognitif pengetahuan berbanding terbalik dengan jumlah soal domain kognitif penalaran. Hal ini lah yang menyebabkan peserta didik lemah dalam mengerjakan soal-soal non rutin yang menuntut penalaran karena jumlah soal penalaran yang sedikit. Hal ini pun diperkuat dengan pernyataan bahwa kemampuan kognitif peserta didik baru sampai pada tingkat pengetahuan belum mencapai tingkat penalaran [14].

\subsection{Perbedaan Soal Ujian Nasional Matematika SMP Tahun Ajaran 2018/2019 dengan soal TIMSS}

Hasil analisis terhadap perbedaan soal Ujian Nasional matematika SMP tahun ajaran 2018/2019 dengan soal TIMSS yang memiliki penyajian soal yang berbeda ditinjau dari domain kognitif yaitu terdapat 18 soal UN yang memiliki domain kognitif lebih rendah dari pada soal TIMSS. 10 soal UN yang memiliki domain kognitif lebih tinggi dari soal TIMSS. 12 soal UN yang memiliki domain kognitif yang setara dengan soal TIMSS.

JARME, Volume 3, No. 1, Januari 2021, 34 - 42. 
1) Soal UN yang memiliki domain kognitif lebih rendah dari soal TIMSS

Soal-soal tersebut memiliki domain konten yang sama, walaupun tidak sama persis. Perbedaan pada soal-soal tersebut terletak pada perbedaan domain kognitif. pada soal UN tersebut semua informasi sudah disajikan pada soal sehingga peserta didik tinggal mengambil informasi dari soal tersebut baik itu berupa gambar, angka, dan kata-kata sehingga hanya mengukur tingkat kognitif pengetahuan dan penerapan saja. Sedangkan penyajian soal pada soal TIMSS dengan lingkup domain konten sama seperti soal UN mampu menyajikan soal untuk mengukur tingkat kognitif penalaran.

2) Soal UN yang memiliki domain kognitif lebih tinggi dari soal TIMSS

Soal UN yang memiliki domain kognitif lebih tinggi dari soal TIMSS adalah soal UN dengan penyajian soal yang lebih komplek yang mampu mengukur tingkat kognitif peserta didik pada domain kognitif tidak hanya pengetahuan dan penerapan saja, tetapi sampai pada penalaran. sedangkan pada konten yang sama seperti soal UN, soal TIMSS hanya mengukur tingkat kognitif pengetahuan dan penerapan

3) Soal UN yang memiliki domain kognitif yang setara dengan soal TIMSS

Soal-soal tersebut memiliki domain konten yang sama, dan domain kognitif yang sama. Walaupun memiliki domain kognitif yang setara namun tetap terdapat perbedaan karena tidak setiap soal-soal yang memiliki domain kognitif yang sama memiliki aspek yang sama. Ada beberapa soal yang memiliki aspek yang berbeda walaupun memiliki domain kogntif yang sama.

\section{Simpulan}

Berdasarkan hasil penelitian dan analisis data yang diperoleh dalam penelitian ini, maka dapat disimpulkan bahwa: (1) butir soal Ujian Nasional matematika SMP tahun ajaran 2018/2019 berdasarkan domain konten taksonomi TIMSS 2019 tidak sesuai dengan yang ditargetkan oleh TIMSS 2019 karena distribusi domain konten pada soal UN tidak sesuai dengan yang diharapan TIMSS. Selain itu terdapat konten yang tidak termuat dalam soal Ujian Nasional yaitu materi transformasi; (2) butir soal Ujian Nasional mateamtika SMP tahun ajaran 2018/2019 berdasarkan domain kognitif TIMSS 2019 mendekati sesuai dengan yang ditargetkan TIMSS 2019 karena terdapat salah satu domain kognitif yaitu domain penerapan yang sesuai dengan proporsi yang ditargetkan TIMSS yaitu 40\%. Selain itu terdapat aspek kognitif yang tidak termuat dalam soal UN yaitu aspek evaluate (mengevaluasi), generalize (menggeneralisasikan), dan justify (memberi alasan) yang termuat dalam domain kognitif penalaran; (3) perbedaan soal Ujian Nasional matematika SMP tahun ajaran 2018/2019 dengan soal TIMSS terdapat tiga kategori yaitu soal UN yang memiliki domain kognitif lebih rendah dari soal TIMSS, soal UN yang memiliki domain kognitif lebih tinggi dari soal TIMSS, dan soal UN yang memiliki domain kognitif setara dengan soal TIMSS. 


\section{Ucapan Terimakasih}

Terimakasih kepada Kepala Sekolah, guru matematika SMP Negeri 1 Puspahiang yang telah memberikan ijin dan membantu kelancaran pelaksanaan penelitian.

\section{Referensi}

[1] Peraturan Menteri Pendidikan dan Kebudayaan RI No. 23 Tahun 2016

[2] Lestari A D \& Siregar A P 2019 Analisis butir soal matematika buatan guru SMP Negeri 1 Mempura Pi: Mathematics Education Journal 2(1) 26-33 doi:https://doi.org/10.21067/pmej.v2i1.2837

[3] Amaliah S 2018 Analisis soal ujian nasional (un) matematika smp/mts se-kota cimahi yang didasarkan pada pemahaman konsep, penalaran dan pemecahan masalah (Skripsi: Fakultas Pendidikan Matematika dan Ilmu Pengetahuan Alam, Departemen Pendidikan Matematika, Universitas Pendidikan Indonesia)

[4] Sunarna S 2016 Analisis butir soal matematika berdasarkan taksonomi timss pada ulangan akhir semester gasal kelas VIII SMP Kabupaten Sukoharjo tahun 2015/2016 (Tesis: Universitas Muhammadiyah Surakarta) http://eprints.ums.ac.id/45756/

[5] Sudrajad M W 2019 Analisis kesesuaian soal ujian nasional matematika smp tahun 2018 berdasarkan kriteria high order thinking skill (hots) pada taksonomi bloom (Skripsi: Fakultas Keguruan dan Ilmu Pendidikan, Program Studi Pendidikan Matematika, Universitas Muhammadiyah Surakarta)

[6] Arminia A 2017 Analisis butir soal matematika ulangan akhir semester gasal kelas vii tahun 2016/2017 berdasarkan taksonomi TIMSS di SMP kabupaten Sukoharjo (Skripsi: Pendidikan Matematika, Universitas Muhammadiyah Surakarta) https://eprints.ums.ac.id/50255

[7] Mullis I V S \& Martin M O (Eds.) 2013 TIMSS 2015 Assesment Frameworks https://timssandpirls.bc.edu/timss2015/frameworks.html

[8] Mullis I V S \& Martin M O (Eds.) 2017 TIMSS 2019 Assesment Frameworks https://timssandpirls.bc.edu/timss2019/frameworks/

[9] Hadi S \& Novaliyosi 2019 Timss indonesia (trends in international mathematics and science study) Prosiding Seminar Nasional \& Call For Papers Program Studi Magister Pendidikan Matematika, Universitas Siliwangi

[10] Moleong L J 2017 Metodologi penelitian kualitatif (Rev. ed.) (Bandung: PT Remaja Rosdakarya)

[11] Sugiyono 2016 Metode penelitian kuantitatif, kualitattif, dan R\&D (Bandung: Alfabeta)

[12] Sugiyono 2017 Metode penelitian kombinasi (mix method) (Bandung: Alfabeta)

[13] Pribadi A, Somakim \& Yusup 2017 Pengembangan soal penalaran model timss pada materi geometri dan pengukuran SMP Histogram:Jurnal Pendidikan Matematika 1(2) 155-128

[14] Setiadi, dkk 2012 Kemampuan Matematika Siswa SMP Indonesia menurut Benchmark International TIMSS 2011 (Jakarta: Litbang Kemendikbud) 